This is an Author's Accepted Manuscript of an article published in SOCIOLOGY OF SPORT JOURNAL, vol. 30, no. 4, 2013, copyright Human Kinetics, available online at:

http://journals.humankinetics.com/AcuCustom/Sitename/Documents/DocumentItem/04_channon_SSJ _20130010_ej.pdf.

\title{
The Rules of Engagement: Negotiating Painful and "Intimate" Touch in Mixed-Sex Martial Arts
}

\author{
Alex Channon \\ University of Greenwich, London, UK \\ George Jennings \\ Universidad YMCA, Mexico City, Mexico \\ Corresponding Author: \\ Dr. Alex Channon, School of Education, University of Greenwich, Mansion Site, Bexley Road, \\ London SE9 2PQ \\ Tel: +44 (0)20 83318255 \\ Email: a.g.channon@gre.ac.uk
}




\title{
The Rules of Engagement: Negotiating Painful and "Intimate" Touch in Mixed-Sex Martial Arts
}

\begin{abstract}
Within the sociology of sport and its related disciplines, martial arts have become increasingly popular sites for research on embodiment, gender and society. While much previous work in this area has focused upon the embodied experiences of either male or female practitioners, relatively few studies have directly addressed the social significance of mixed-sex practice. In this empirically-focused paper, we draw on qualitative, semistructured interviews with both male and female long-term exponents of various different martial arts disciplines in England, exploring experiences of inter-sex touch within training. Within a social-constructionist, feminist framework, we suggest that heteronormative, patriarchal and paternalistic gender structures can potentially be challenged through sustained mixed-sex practice. As such, this article contributes to work on transformative sporting bodies, martial arts and gender subversion.
\end{abstract}

\section{Introduction}

In recent decades, an expanding literature on martial arts has explored practitioners' combative abilities as an area of interest for understanding gender. Particularly, researchers since the 1990s have examined women's participation in combat sports (Halbert, 1997; Hargreaves, 1997; Mennesson, 2000; Paradis, 2012), self-defence (De Welde, 2003; Hollander, 2004; McCaughey, 1997; 1998) and traditionalist martial arts (Castelnuovo \& Guthrie, 1998; Guthrie, 1995). As with some earlier works by feminist sociologists of sport (e.g. Lenskyj, 1986; Theberge, 1987), these works drew associations between women's physical, combative ability, alternative schemes of embodiment, and resistance to patriarchal renditions of feminine propriety. Specifically, they suggested that martial arts training could involve both physical and psychological transformations, as women effectively engage in "un-learning" the physically weak and passive forms of feminine comportment into which they are socialised by a broadly heterosexist, patriarchal culture. Embodying greater physical power and self-confidence, such women defy traditional conceptions of the "frail" female body (Dowling, 2000) and passive feminine subjectivity. Thereby exorcising "the bodily memories that a sexist culture has lodged in them" (McCaughey, 1998, p. 286), female martial artists are able to transform themselves via explicitly resistive forms of embodiment.

Moreover, such scholars have suggested that these women's examples also impact upon broader constructions of sex, as successful female martial artists become potent signifiers of an alternative, subversive rendition of gender which runs against normative boundaries shaping typical understandings of hierarchal, sexual difference. Given the directly embodied nature of martial arts, and the close connection between fighting ability, physical domination and heterosexist notions of masculine hegemony (e.g. Connell, 1995; McCaughey, 1997; Messner, 2002), bodily practices aimed at developing female physical power are therefore 
seen to challenge the discursive articulation of men as "naturally", and thus inevitably, dominant over women. It has thereby been argued that women's martial arts training can serve as a form of "physical feminism" (McCaughey, 1997), as constructing powerful female bodies and subjectivities within martial arts can challenge the central notion of "natural" male superiority within heteronormative, patriarchal culture.

As such research has expanded however, investigations into martial arts as transformative gender practices have coalesced around tendencies to explore either women's or men's training. With some recent exceptions (Guérandel \& Mennesson, 2007; Lökman, 2010; McNaughton, 2012; Spencer, 2011), there has been relatively little attention to sex-integrated training, much less direct focus on its transformative potential. Yet in other physical cultural settings, feminist scholars have explored mixed-sex participation, suggesting that personal empowerment, along with broader challenges to hierarchal gender discourse, can be strengthened immensely when men and women jointly experience the potentials of differently sexed bodies (Anderson, 2009; McDonagh \& Pappano, 2008; Travers, 2008; Wachs, 2005). This indicates that investigating mixed-sex training might yield richer analyses of the transformative value of women's involvement in martial arts; a task we turn to in this paper.

\section{Methodology}

Our data are drawn from two long-term, qualitative sociological studies undertaken in England between 2006 and 2011. As "martial arts" is a broad and illusive term, these studies sampled a range of styles to capture different technical, organisational and ideological understandings of learning to fight/improving fighting abilities - which forms our conceptualisation of martial arts in this paper $^{1}$. The range of arts represented included Brazilian jiu jitsu (BJJ), karate, kickboxing, kung-fu, mixed martial arts (MMA), muay thai, and taekwondo, among others. While many recent martial arts studies have ethnographically explored specific, localised settings (e.g. Bar-On Cohen, 2009; Rao, 2008; Ryan, 2011; Spencer, 2011), we adopted a case study interview design, which enabled the examination of social themes beyond localised contexts (Flyvbjerg, 2006) and within a diversity of disciplines. Both male $(n=27)$ and female practitioners $(n=22)$ were interviewed, drawn from clubs based in the South West, South East and East Midlands regions of England. Participants identified predominantly as White British $(n=33)$, with some British Asian $(n=1)$, Black British $(n=2)$, British Chinese $(n=5)$, British mixed-race $(n=3)$, and White 'Other' $(n=5)$. Participants were aged between 19 and 69 years old, came from a range of socioeconomic backgrounds, and all self-identified as being heterosexual. Although we do not take this sample to represent all English/England-based martial artists, nor the entirety of systems practiced in England, it does provide an exploratory illustration of topics and issues emerging in wider martial cultures. 
Using a semi-structured interviewing approach, we explored the past and current experiences of both instructors and students, and the influences on their martial arts training and teaching. These accounts, including primary and follow-up interviews, were transcribed and thematically analysed by either data collector, and then exchanged for secondary analysis (Heaton, 2008). We removed any identifying personal details, giving self-selected pseudonyms to participants in order to protect their anonymity (Kvale \& Brinkmann, 2008). Our subsequent analysis was assisted by our different embodied experiences, having each practiced numerous traditionalist, sports-oriented, health-meditative, and weapons martial arts throughout our training careers. Although we are investigating gender as White British, "middle-class", heterosexual males, our differing embodied experiences and sociological perspectives led us to consider alternative thematic and theoretical possibilities (see Channon, 2012a; Jennings, 2010). Eventually, we decided that feminist, social-constructionist understandings of gender would best help explain the significance of the varied "rules of engagement" ${ }^{\prime 2}$ which structured (and were structured by) the embodied experiences within mixed-sex martial arts.

\section{Theorising the Sexed Body as Socially Constructed}

Exploring embodied aspects of martial arts is particularly relevant to feminist efforts, given the centrality of bodies and bodily practices to heteronormative discourses supportive of hierarchal sexual difference, and also strategies of resistance to the inequity implied within such structures. As outlined by feminist theorists such as Bordo (1993[2003]), Butler (1990) and Grosz (1994), we conceive of the embodied, gendered subject as a flexible, changeable entity, whose "normal" sexed parameters are shaped by individuals' repeated performance of socially-constructed, normative gender discourse. In this analysis, "our identities, gendered and otherwise, do not express some authentic "core" self but are the dramatic effect (rather than the cause) of our performances" (Bordo, 1993[2003], p. 289, original emphasis). Thus, gender is considered something which individuals "do", in line with normalised discursive structures of propriety which prevail throughout specific social locations (West \& Zimmerman, 1987; Butler, 1990). And, as gender is "done", exercised repetitively through and/or upon the differentially sexed body, it helps to create the illusion of a biological essence, through a "felicitous self-naturalisation" (Butler, 1990, p. 45) which disguises the cultural roots of much lived difference between sexed bodies. This naturalisation helps to consolidate the inequalities embedded within hierarchal arrangements of sex, "because it claims a naturalness that denies challenge" (Bryson, 1990, p. 175), insinuating that patriarchal structures are expressive of a natural order, rather than by-products of cultural discourses and practices which might be critiqued and changed.

Therefore, rejecting an essential, "core" gendered self raises the possibility of diverse, alternative and subversive forms of embodiment, as it denies the binary logic of natural determinism and the inevitability of sexual hierarchy which this typically presupposes. As Deutsch (2007) claims, just as gender is often "done" in ways which typically reproduce 
patriarchal inequality whilst reifying narrow, heteronormative forms of male and female identity and embodiment, gender may also be "undone", as a means of resisting or reformulating the structural division of the sexes constitutive of patriarchy (cf. Butler, 2004; Lorber, 2000). We therefore hold that sociological interest is rightly directed towards any embodied practice which involves potential breakages from these otherwise socially dominant codes, for as Butler explains, "the strange, the incoherent, that which falls "outside", gives us a way of understanding the taken-for-granted world of sexual categorisation as a constructed one, indeed, as one that might well be constructed differently" (1990, p. 149).

In our experience as practitioner-researchers, the phenomenon of mixed-sex training certainly "falls outside" of the parameters of everyday, embodied sexual "normality". Thus, we aim for our present study to make a contribution to the extant literature on martial arts, and mixed-sex sport more generally, as a potential site for the subversive "undoing" of gender (Deutsch, 2007).

\section{Problematic Touch in Martial Arts}

Touch is receiving increasing academic attention as researchers move beyond traditional visual and oral foci of experience (e.g. Classen, 1993; Macpherson, 2009; Paterson, 2006; Sheets-Johnstone, 2011; Sparkes, 2009). Here, the lived body is paramount as a feeling, thinking and moving human being with shifting intersubjective experiences. Hence, exploring touch helps highlight embodied opportunities and tensions in mixed-sex martial arts training, and given the relative centrality of touching in many of the disciplines explored here, this provides an interesting medium for investigating martial artists' experiences (e.g. Green, 2011; Spencer, 2009). The types of touching involved in martial disciplines are varied, ranging from short bursts of explosive, dynamic touch via punches, kicks and other striking methods ("hitting"), to the struggling, wriggling, body-to-body contact of "grappling", and also "soft" forms of partnered practice where touching is sustained, slow and subtle. Touch may be prolonged for hours, with points of contact varying from hands, forearms and ankles to entire bodies. "Intimate" parts may be in close proximity, with bodies entwined, exchanging sweat or blood as training partners practice in relatively intense engagements. Furthermore, touch may involve pain and risks of injury, as martial artists hit, throw, pin and choke resisting opponents in competitive or "realistic" engagements. For many of the interviewees, "hurting" was almost always accepted as a routine, normalised element of training; as kung-fu instructor Dan summarised, "ninety-nine point nine per-cent of the time, sparring hurts".

As our research developed, it soon emerged that both "intimate" and painful forms of touch posed particular problems within sex-integrated settings. Whenever men and women were training together - which, in our own experience as with those of our participants, was fairly common - a number of specifically gendered anxieties arose around touch. In particular, 
these tended to involve either an aversion to "hurting" one's training partner, or a fear of sexual impropriety. In what follows, we explore these problems, before detailing how practitioners negotiated ways of solving them which have some bearing on the transformative potential of mixed-sex training.

\section{Hitting, Hurting, and Holding Back}

Martial arts are practices which are typically grounded in combative physicality; to become a martial artist often requires one to perform feats which may, outside training halls, appear "violent", potentially causing harm to one's own or others' bodies ${ }^{3}$. While most practitioners dismiss the implication of "violence" within martial arts (cf. Back \& Kim, 1982), the embodied sensation of performing techniques which are likely to inflict pain, or somehow incapacitate training partners/competitive opponents, nevertheless stands outside of many people's everyday experiences and notions of social propriety. Within the context of mixedsex training, this is even more the case. Here, two particularly salient concerns arise: the general tendency for inexperienced female practitioners to be unwilling to "hurt" their training partners, and for male martial artists to be deeply reluctant to "hurt" women in particular.

Firstly, women's hesitance toward inflicting pain on others is a theme identified in previous works on women's (sex-segregated and integrated) martial arts training, as dominant discursive constructions of gender typically preclude the association of combative physicality and femininity (De Welde, 2003; Lökman, 2010; McCaughey, 1997). Simply not believing themselves capable of performing powerful fighting techniques may represent a key difficulty for many women in martial arts, but moreover, a "feminine" subjectivity which emphasises a supposedly gentle, "nurturing" female nature can leave some women feeling deeply unsuited to even attempting the training which might develop such abilities, as they become unsettled at the prospect of hurting someone (Lökman, 2010). While this was not a problem shared among all of the women we interviewed, some, such as muay thai and MMA competitor Sylvia, had initially felt uncomfortable with hitting others. Although eventually developing a more "aggressive" approach to sparring, she later encountered difficulty with prompting this transition among others:

I remember it was only two weeks into my training, (my instructor) invited me into the ring... and I was terrified, I was so terrified, I did not know what to do because like I didn't wanna hurt him... (it was) more about causing other people pain and grief and things like that. I'd rather get hurt than hurt them, if that makes sense.

One of the big difficulties I find (now) is that I don't want the (inexperienced) girls to get turned off by the aggression that I show them. But at the same time, I want them to do the same sort of aggression, so it's quite difficult to see that and get it right.

Drawing on a discursive construction of idealised femininity as the archetypal opposite of masculinity, this reluctance resonates with the ideological separation of women from "male 
culture" advocated by some cultural feminists (McCaughey, 1997). This potentially hinders individual women's progression in learning martial arts and embodying greater combative physicality, thus problematizing women's (and mixed-sex) martial arts as a socially transformative phenomenon, as outlined above.

Secondly, the issue of "hurting women" arose as a profound moment in men's training careers among all of our interviewees' accounts (Channon, 2013). A frequently recurring theme within our respective studies was the tendency for men to "hold back" when practicing with or sparring against women. While most routine martial arts practice requires a certain degree of restraint, this becomes problematic when men excessively withhold from engaging with female training partners, who they assume to be inadequately resilient to withstand being hit, thrown or grappled with at the same intensity as men (Guérandel \& Mennesson, 2007; McNaughton, 2012). Key here was the recognition that such men held back more against women than was thought appropriate or necessary; according to taekwondo instructor John,

You see it a lot, this mental block for guys to hit girls. You'd have a guy who's only been sparring for three months against a girl who's been training for more than four years and can clearly handle herself very well, and he'll still think 'oh, it's a girl, I better go light on her", even though she can take him out easily.

For many such experienced female martial artists, this was seen to undermine their training experiences and sense of belonging within clubs, and even threaten their identities as martial artists; as Sara noted, "there's no point in me calling myself a kickboxer if I've never been kicked!" For others, including kung-fu practitioner Beth, sympathy with men's unease did not preclude strong feelings of disappointment and frustration with the treatment they often received from apparently "chivalrous" partners:

(Men) have to cope with the fact that for their whole lives they've been told not to hit girls... you can't just tell them to get over it and expect them to drop it straight away.

It gets so frustrating... sometimes I just feel like saying, will you fucking hit me, for once? Because otherwise it's pointless me being here.

Many of our male interviewees described the difficulty of hitting women in terms of socially normative models of sexual propriety. Some men even cited an understanding of antirape/domestic violence discourse as a problematic element of their own and other men's practice with women who wanted or needed to be hit, thrown or grappled. As karate and MMA practitioner Elliot explained,

It's one of those things... you hear about it in the news, about men hitting women, abuse, it's just like you don't want to be one of those men. It sounds stupid to compare it but that's what comes into your head when you think, "ok, I'll really hit her this time". 
Therefore, women's embodiment of a passive/non-violent femininity, and men's adoption of a paternalistic approach towards women, threatened to restate conservative renditions of sex difference within integrated training. Through the "repeated performance... of discourses of gender" (Weedon, 1999, p. 122), this reproduced an embodied hierarchy whenever men's and women's adherence to these gendered norms prevented women from having adequately tough, painful, or forceful training, which then hindered such women's development of toughened bodies, combative dispositions, and fuller martial competency (cf. Green, 2011; Spencer, 2009). As such, men's fear of hurting women, along with some women's reluctance to hurt anyone, could potentially neuter the transformative, subversive quality of mixed training, as these phenomena simultaneously endorsed discourses of male physical superiority, whilst preventing women from effectively developing combat-ready bodies/bodily dispositions.

\section{Heteronormative Sexuality and "Intimate" Touch}

Concurrent with research on US mixed-sex collegiate and scholastic wrestling competition (Fields, 2008), further problems for integrated training revolved around the primacy of heterosexuality for understanding sustained or "intimate" body-to-body contact between men and women. The problem of relations between men and women being principally viewed as carrying sexual connotations has also been discussed elsewhere, such as in Messner's (2002) account of the violently misogynistic sexism within male sports teams ${ }^{4}$. Although manifested somewhat differently, this largely normative status of heterosexuality as a way of understanding (physical) interactions between men and women often hampered the training effectiveness of mixed-sex martial arts.

Firstly, the implications of overstepping personal boundaries through "improper" touch could impede training engagements, as particularly novice martial artists would avoid certain practices or partners for fear of being considered guilty of sexual impropriety. Simon recalled his earliest experiences of mixed-sex karate, highlighting how his unease at touching female partners' breasts impeded sparring practice:

It was really light sparring, so we weren't exactly hitting each other, but I threw a few good shots and then I caught her in the chest. And then I was instantly going, "God I'm so sorry," you know, stopped sparring... It's just that (mixed-sex practice) is not what people are used to and not what they expect.

Women also found the initial foray into mixed-sex training to involve awkward deliberations around the sexual implications of touch. According to MMA and BJJ practitioner Rachel,

I remember training with this woman and feeling so strange, she didn't seem to have any boundaries at all, I saw her mount a guy and try to choke him with her breasts, and then she's like, "right, now you try it!" I don't think so! 
The intimidating prospect of improper touch, or of risking being thought to have touched another's sexual organs improperly, thereby prevented some practitioners from focusing on the development of skills and embodied sensitivities essential in many martial disciplines (cf. Brown \& Johnson, 2000), and thus could become a hindrance to effective, mixed-sex training 5 .

Meanwhile, some interviewees also discussed problems associated with heterosexual relationships forming in training environments. These were often described as potentially undermining both the seriousness of training, and the social status of female martial artists. Firstly, the frequency and intensity of touch in training was seen as being quite unlike the physicality involved with social interactions outside of this context, producing a form of "fast-track" intimacy between practitioners. According to some, there was every possibility that this could help form (hetero)sexual relationships ${ }^{6}$, which could be problematic whenever the connections established in training were interpreted as romantic, leading to short, ill-fated affairs. As MMA and BJJ instructor Andy described,

I've got girls who are coming up in the game, and you know, it's not that they're skanks, (but) they might meet a guy here and they're creating close bonds through training... (they) get really close, like you are in training, physical contact, sweating on each other... I wish I could make a rule against it, ban them from sleeping with each other... It's always ended badly, always. Usually they split up and the girl leaves, or they'll have a one-nighter and the girl will be too embarrassed to come down again.

Further to this, several female interviewees felt that being seen as sexually available to their male training partners may threaten to compromise their positions as respected members of clubs. Discussing her distaste for "MMA groupies" - women she believed joined clubs in order to meet and have sex with male MMA fighters - Rachel told how:

There's a lot of those women who come into it thinking "I can meet fighters that way", and then they go "oh look, I'm a fighter too", and they get to meet the guy, do (sexual) stuff, and they move on to the next guy, and it's all a bit gross... What does it say to the guys? It might make them think we're all just there to get laid.

Therefore, while the anxiety and embarrassment surrounding the (hetero)sexualisation of touch could adversely affect both men's and women's training, the formation of sexual relationships was frequently thought to pose greater problems for female practitioners than their male partners. That it was women who were seen as more likely to be shamed out of clubs following sexual contact, or seen as "groupies" or "skanks" thanks to others' prominent indiscretions, speaks to the enduring double standards of heteronormative sexuality (Crawford \& Popp, 2003). Further, the gendered underwriting of this arrangement emphasised men's centrality in martial arts spaces, most often casting women as the ones at fault when such complications arose ${ }^{7}$. Thus, not only could such sexualisation make mixed training awkward and problematic, it also tended to restate dominant discursive constructions of gendered sexuality, seen here as particularly disadvantageous to women. 


\section{Towards Effective Mixed Training}

The problems associated with touch in mixed-sex practice are thereby seen as the products of the "doing" of gender, vis-à-vis the performance of heteronormative discourses of binary sexual difference, and the concurrent maintenance of unequal power structures characteristic of patriarchal culture (Deutsch, 2007; Lorber, 2000; West \& Zimmerman, 1987). From a position sensitised to the progressive, transformative capacity of both integrated sports and women's development of combative physicality (e.g. De Welde, 2003; McDonagh \& Pappanno, 2008), these embodied tensions represent a significant frustration to the gendersubversive value of mixed-sex martial arts. But, needless to say, gendered anxieties over painful and "intimate" touch were rarely considered problematic by our participants for this reason. Instead, it was that they might be disruptive to training, and thus harmful to the development of men's and women's martial competencies, that commonly saw them become the object of practitioners' ire.

Yet rather than argue against mixed-sex training, our interviewees described how they had attempted to overcome such problems, which ranged from calculated strategies for the effective "undoing" of gendered limitations, to more incidental experiences and discoveries destabilising the discursive basis for their own and others' anxieties. While motivated typically by a desire for better, more effective martial arts training, these practices typically involved challenging the primacy of (hetero)sexist, binary conceptions of sex difference and sexuality which, in turn, taught martial artists alternative truths about sexed bodies and gender relations. Thus, it was possible to reject discourses stressing natural, binary and hierarchal differences, replacing such with bodily understandings developed via mixed-sex training.

\section{"Hit, or Be Hit"}

While various pedagogical approaches are used within the curricula of different martial arts, a common denominator among our participants' experiences was a belief that partnered practice, especially sparring (or "rolling", in grappling-based arts), was the most effective method for developing "realistic" or competitive martial competency (McCaughey, 1997; Wacquant, 2004). Finding ways of overcoming the anxieties many practitioners felt regarding the potential to "hurt" their training partners, which could otherwise negate the effectiveness of sparring/rolling, was therefore an important task, and instructors often sought ways to challenge tensions between supposed gender propriety and combative physicality.

One such strategy, aimed principally at women anxious about "hurting" others, involved foregrounding the importance of physical assertiveness for self-defence. Also forming a key element in many men's moral rationalisations of their development of fighting skills (being quite common in our own experiences), and concurrent with findings from research into 
women's feminist-oriented self-defence programmes (e.g. Hollander, 2004), this recognition typically involved direct discussions of the moral legitimacy of forcefully protecting one's self against another's violent transgressions. Some instructors, such as Andy, described their approach to teaching self-defence to women, wherein some women's distaste for causing harm was explicitly framed as inappropriate for the high-stakes realities of "real" fighting:

The amount of women who say to me, "I would never bite anyone", and I go "ok, so a guy's raping you, probably gonna kill you, steal all your money, and you won't bite him?"... (they) wanna hear, "just hit him here and he'll go unconscious"... I couldn't lie to them and say "oh yeah, just do this and you'll be fine." It's gonna be a fight, I could teach you how to win that fight, it won't be pretty and you will get hurt but you'll win that fight, you won't get raped or killed, you'll cause some serious damage to (your attacker) and you'll get away. He won't try it again, and to me, that's the way to go.

While such discursive strategies urged women to reject their unease with harming others, a second method was to appoint female instructors, and make frequent use of senior female club members to demonstrate techniques, in order to visibly associate martial competence and toughness with a female role model. Together, these helped to disassociate martial artistry from any imagined, exclusive link with men and masculinity, or the sense that men remained more centrally important to the social spaces of martial arts clubs than did women. Many instructors - male and female - told of how they tried to establish such situations as often as possible, and according to BJJ competitor and part-time instructor Louise,

I see it as my number one role at the moment, inspiring the talented young girls who come to the club... And I think one of the best ways to do that is to show what I can do, and that usually means practice with the men, demonstrate to everyone that women can be just as good.

While this strategy was regarded as effective in "inspiring" young women to develop as martial artists beyond the confines of passive, unassertive femininity (De Welde, 2003), it was also useful in challenging male hesitations towards "hurting" women. Junior instructor and competitive kickboxer Helen told how "when (men) actually see what I can do, it's amazing how (their) perceptions change". Yet this experience often required going beyond the simple visibility of technical competence, as it was felt that the toughness and capability of female martial artists was best revealed through their physicality.

According to our female interviewees, this often involved "teaching men a lesson" about their fighting abilities; when men would refrain from striking or throwing them, or do so only lightly and thus not in ways conducive to the desired training outcomes of greater toughness/resilience, these women would respond by "hitting them hard enough to make them want to hit back" (McNaughton, 2012, p. 7). Forcing men onto the defensive thus became the most effective means of challenging men's paternalistic reluctance to hit; kickboxing instructor Marie commented: 
If (men) don't listen and refuse to hit me then I'll smack them, pure and simple... if someone thinks I'm not good enough for this then they'll have to find out the hard way that I am.

This sentiment was echoed by many, as was the belief that this formed an effective way of encouraging men to view women on equal terms as fellow martial artists. For instance, Rachel described how beating men at a competitive tournament helped better establish herself among the men with whom she trained:

You do sort of prove something to (men) when you beat them. They treat you differently after that, like some of them will be happy to partner with you or ask you for help more often... I don't think they'll understand it until they've done it or at least seen it. It's hard to see inside something you don't do.

The notion that men's ideas about women's (bodily) capabilities are changed after "doing" such physical exchanges on the mat was also stressed by most of the male interviewees. Gaining martial arts experience, and the concurrent adoption of a relatively de-gendered perspective towards hitting, echoed the process of gender socialisation identified earlier, as men and women learn about their own and others' bodies through repeated performances, which eventually provide "dramatic symbolic proof" (Messner, 1988, p. 200) of alternative conceptions of sex difference. Simon gave an account of his embodied journey in integrated martial arts, highlighting the centrality of hitting to such changes in his own perspective:

I remember when I first got beaten by a girl, she knocked me out I guess, elbowed me in the head, and that was a bit of a moment when I thought well, I should definitely take (women) more seriously and not feel weird about (hitting them) when they can hit like that. You need to go through a few weird moments first I reckon, like how I got knocked out, and then when you finally get it... you approach it all differently.

Simon's account demonstrates the importance of actually performing this alternative discourse about bodies and fighting ability, which at first seems "weird" but then ultimately makes normal the implied, physical equality within the exchange of blows between men and women.

\section{Sexuality and Non-Sexual Intimacy}

While practical steps taken to challenge "chivalrous" paternalism and passive feminine styles largely revolved around pedagogical strategies rather than overt "rules of engagement", the problems stemming from the sexualisation of male-female "intimate" touch called for some more formal, if personalised rules, in addition to subtle/implicit methods. Firstly, while instructors like Andy lamented being unable to ban (heterosexual) relationships within clubs, some individuals told us of their own selfimposed regulations against becoming "involved" with their training partners as a means of avoiding the pitfalls associated with intra-club romance. Helen told how: 
I made a promise when I came in here that I wouldn't ever get involved romantically with anyone in the club, and it's the best decision I could've made... I know I've (received) much more respect through never having been involved with anyone...It's kind of like law now... people know that my sole purpose is that I'm here to train, nothing else. And it works.

By publicising their sexual unavailability, whilst vocally and performatively demonstrating their singular commitment to training, women like Helen directly attempted to undermine the heteronormative assumptions otherwise seen to be threatening their equal status in integrated spaces. And, in thus challenging the potential for men to view women primarily in sexual terms, Helen and those like her considered themselves able to develop a platonic intimacy which was highly valued as conducive to supportive and effective training environments (cf. Green, 2011; also Anderson, 2008).

The sexualisation of male-female touch was challenged in other ways than simply refusing the possibility of sexual involvement with training partners. Recognising the anxiety felt by many men towards "inappropriately" touching women, some took steps to reduce the prominence of their "intimate" parts and thus the likelihood of this occurring. Emma proposed that equipment which enabled her to "hide" her breasts provided a solution to the anxiety male training partners may otherwise feel:

Blokes are very wary of my chest area. They don't really want to go near it because it's obviously a very personal space. So I've had to find training aids to overcome this, and now I've got a simple kind of sports bra top with plastic cups... And it's perfect, because it takes that out of the equation. It doesn't matter if they touch.

Consequently, protective gear, and also some training uniforms, allowed the sexed body to shrink from view and touch, enabling both de-sexualised forms of close contact, as well as a disappearance of (some of) the body's sexually differentiating characteristics. Therefore, and as Louise suggested, "the gi (uniform) is like a barrier", enabling easier mixed-sex touching, and ultimately facilitating integrated practice.

However, it was felt by some others that encouraging continual exposure to mixed practice was a more effective way to move past the awkwardness associated with these forms of touching, addressing the issue in a more fundamentally corrective way. Here, experience within mixed-sex training could, over time, lead to practitioners "getting over" the sexual implications previously associated with male-female touching. According to Andy,

At first... people think "Oh God, is it sexual? Is it wrong?" People ask themselves these questions (but) eventually they know it's just training and it's nothing to do with (sex), and that goes. 
As such, some instructors instigated pedagogical routines designed to normalise "intimate" touch, such as wing chun instructor Steve, who reflected on how physical intimacy in training differed to everyday life:

We spend a lot of time holding, touching, placing a hand on people's bodies. Whereas in normal society you wouldn't walk up to a stranger and say, "right, put your hands on my chest", a total stranger would walk through the door here, and you would say, "you've got to put your hand on my chest." You've instantly broken down the barriers (that people) deal with on a day-to-day basis.

To that end, Steve developed exercises to encourage students to become comfortable with close range and otherwise "intimate" forms of touch, such as hugging after immobilising a punch. The pedagogical use of this particular touch-based training was important for removing previous inhibitions and anxieties through continual, long-term exposure. And, just as with the refusal to engage in sexual relationships, becoming accustomed to non-sexual, physical intimacy was seen to facilitate more effective forms of mixed-sex training.

In this regard, many interviewees described such sustained, close-quarters touch as vital in the development of self-defence ability potentially useful in "real" situations. As discussed above, it was universally agreed upon that both men and women needed to engage with "serious" (i.e. non-sexualised), sustained and intense partner training in order to develop an eclectic set of dispositions for self-defence (Brown \& Johnson, 2000). This was considered especially true for women learning how to self-defend against potential (male) attackers, thus becoming even more important in the context of integrated training. As kung-fu instructor Evelyn stated,

Everything we do in kung-fu has its application. And I always said that touching is important because if you've never had someone grab you then when it happens on the streets you'll be freaked out by it and have no answer to it... Training is only good if it's applied to real life, so that's why we do all this (touching) stuff.

While such discursive rationalisations of partner training featuring sustained, "intimate" contact included the further possibility of gaining a competitive edge in sparring tournaments, it was also thought useful for practitioners examining or attempting to heal one another's injuries - a fairly common practice in many martial arts clubs (cf. Zarrilli, 1998). According to wing chun and Chinese massage practitioner Sarah, who would offer on-the-spot help to injured training partners,

(Men) get a bit freaked out when I start pressing (pressure) points, thinking, "Sarah, what are you doing?!" They don't quite understand it. Because I understand it and have demonstrated it on myself, I know it works. 
In such ways as these, martial artists who were de-sensitised to touching and being touched by others were thought to hold a number of advantages over those whose lack of experience, and over-sensitive disposition, ill-suited them to the physicality of martial arts. Thus, finding ways to reduce the sexualised meanings of touch in training were a key consideration for many instructors, particularly given the parameters of heteronormative expectations otherwise shaping (mostly) novice martial artists' approaches to mixed training environments. In this way, the objectives of martial arts training, particularly in integrated groups, aligned with subversive ways of "un-doing" heteronormative gender codes, making the practice particularly meaningful for feminist understandings of physical culture.

\section{Concluding Thoughts}

Experiences of inter-sex touching formed key concerns for many participants in our studies, as the practice of integrated martial arts training raised numerous embodied tensions. Causing pain to women was a chief concern among many men, while the sexual connotations of close physical contact, chiefly with "intimate" parts, was something which men and women alike would try to avoid. In this sense, especially among inexperienced martial artists, heterosexist and hierarchal discourses stressing binary gender difference, and the primacy of sexuality for understanding inter-sex physical contact, would lead participants to adhere to codes of propriety for the differential treatment of men and women. These heavily gendered "rules of engagement" were criticised by our interviewees as impeding the development of fighting abilities, but following their prolonged engagement with martial arts, and formulation of explicit strategies for circumventing such gendered practices, they told us how their experiences often led them to view the sexed body, and therefore go on to behave, in different ways.

In this regard, alternative discourses arose based upon the normalised performances of combative prowess by both sexes, and as participants "got over" their reservations and came to reject sexualised or paternalistic interpretations of touching each other's bodies. Kung-fu instructor Jack told how he eventually viewed female training partners not primarily as "women" but as "martial artists", adding that "this experience forces you to look at (women) differently"; Helen spoke of changing men's and women's perceptions of female bodily capabilities; and Andy described how his students could "grow as people" by seeing physical intimacy as beyond being purely "sexual". Such discourses were then used to rationalise "serious" forms of intense, prolonged training as equal practitioners, as the explanatory structures of martial arts came to eclipse typical gendered understandings of the body (Guérandel \& Mennesson, 2007). Hence, the physical dimensions of mixed-sex martial arts practice became a lived-out "undoing" of gender, impacting upon the practitioners' understandings and embodied performances of sex difference. While this was not a uniform experience across all of our interviewees or among all of their training peers, our findings nevertheless indicate that the potential to subversively "undo" gender exists within mixed-sex martial arts, as within other integrated physical cultures (McDonagh \& Pappano, 2008). 
We therefore suggest that our findings make a meaningful contribution to the sociology of sport, embodiment, martial arts and gender, and assert that a focus on sex integration has much to offer future investigations interested in similar themes. For instance, more research on mixed-sex martial arts would be beneficial across nations, examining how such issues may connect and differ between diverse cultures, while historical research, contributing to efforts such as Green and Svinth (2003), could illuminate the long-term developments of mixedsexed pedagogies and training. There is also scope to explore how the transformative lessons of such training affect martial artists' wider lives, including sexual, parental and familial relationships - areas we have not addressed here due to spatial constraints. Finally, it remains to be seen whether same-sex touch between heterosexual and homosexual (or, indeed, between two homosexual) participants bears any added significance to that already discussed. Given that neither of us has yet encountered any openly homosexual participants during our research means we are unable to confidently comment on this, leaving open another possibility for future investigations.

\section{Notes}

1 As discussed elsewhere (e.g. Chan, 2000), defining "martial arts" is highly problematic, and we are not forwarding this conceptualisation as an answer to on-going debates among scholars and practitioners. Rather, given that links between fighting ability, physical domination and sexual hierarchy are central to gender analyses in this area, this definition is arguably the most useful here.

2 We use this term to refer to a number of norms/behaviours based on martial artists' adherence to either heteronormative, paternalistic discourses of gendered propriety, or some conscious attempt to challenge the limiting effects of such notions and practices, within the course of their training.

3 Some styles of martial arts - popular taijiquan for instance - often lack this directly combative element. Our focus in this paper is upon those many styles within which the development of combative prowess is central; future efforts into exploring mixed training in such "soft" arts may reveal different themes to those discussed here.

4 See Anderson (2009) for an alternative view.

5 The same problems rarely arose around same-sex touch (see note 6).

6 By contrast, homosexual relationships were not discussed; unlike inter-sex touch, same-sex touch was not primarily interpreted in terms of sexuality, further illuminating the depth of how heterosexist assumptions shape inter-sex interactions.

7 Attitudes among men towards female club members were considered, by some, to differ between martial arts styles, arising out of such men's constructions of masculine propriety vis-à-vis comparative conceptions of "traditional" martial arts and "mainstream" sports cultures. For a more thorough discussion, see Channon (2012b).

\section{References}

Anderson, E. (2008). 'I used to think women were weak': Orthodox masculinity, gender segregation, and sport. Sociological Forum, 23(2), 257-280. doi: 10.1111/j.15737861.2008.00058.x 
Anderson, E. (2009). Inclusive masculinity: The changing face of masculinities. Abingdon: Routledge.

Back, A., \& Kim, D. (1982). Pacifism and the Eastern martial arts. Philosophy East and West, 32(2), 177-186. Retrieved from http://www.jstor.org/stable/1398715

Bar-On Cohen, E. (2009). Survival, an Israeli ju jutsu school of martial arts: Violence, body, practice and the national. Ethnography, 10(2), 153-183. doi:

$10.1177 / 1466138109106300$

Bordo, S. (1993[2003]). Unbearable weight: Feminism, Western culture, and the body. Los Angeles: University of California Press.

Brown, D., \& Johnson, A. (2000). The social practice of self-defense martial arts: Applications for physical education. Quest, 52(3), 246-259. doi: 10.1080/00336297.2000.10491713

Bryson, L. (1990). Challenges to male hegemony in sport, in M. Messner \& D. Sabo (Eds.) Sport, men, and the gender order: Critical feminist perspectives (pp.173-184.). Champaign: Human Kinetics.

Butler, J. (1990). Gender trouble. Abingdon: Routledge.

Butler, J. (2004). Undoing gender. London: Routledge.

Castelnuovo, S., \& Guthrie, S. (1998). Feminism and the female body: Liberating the Amazon within. London: Lynne Rienner.

Chan, S. (2000). The construction and export of culture as artefact: The case of Japanese martial arts. Body \& Society, 6(1), 69-74. doi: 10.1177/1357034X00006001005

Channon, A.G. (2012a). Way of the discourse: Mixed-sex martial arts and the subversion of gender. (Unpublished doctoral dissertation). Loughborough University: UK.

Channon, A.G. (2012b). Western men and Eastern arts: The significance of Eastern martial arts disciplines in British men's narratives of masculinity. Asia Pacific Journal of Sport and Social Science, 1(2-3), 1-17. doi: 10.1080/21640599.2012.751170

Channon, A.G. (2013). 'Do you hit girls?' Some striking moments in the career of a male martial artist, in R. Sánchez García \& D.C. Spencer (Eds.), Fighting scholars: Habitus and ethnographies of martial arts and combat sports (pp.95-110.). London: Anthem.

Classen, C. (1993). Worlds of sense: Exploring the senses in history and across cultures. London: Routledge.

Connell, R. (1995). Masculinities. Cambridge: Polity.

Crawford, M., \& Popp, D. (2003). Sexual double standards: A review and methodological critique of two decades of research. Journal of Sex Research, 40(1), 13-26. doi: $10.1080 / 00224490309552163$

De Welde, K. (2003). Getting physical: Subverting gender through self-defense. Journal of Contemporary Ethnography, 32(3), 247-278. doi: 10.1177/0891241603032003001

Deutsch, F.M. (2007). Undoing gender. Gender \& Society, 21(1), 106-127. doi: $10.1177 / 0891243206293577$

Dowling, C. (2000). The frailty myth: Redefining the physical potential of women and girls. New York: Random House.

Fields, S.K. (2008). Female gladiators: Gender, law, and contact sport in America. Chicago: University of Illinois Press. 
Flyvbjerg, B. (2006). Five misunderstandings about case study research. Qualitative Inquiry, 12(2), 219-245. doi: 10.1177/1077800405284363

Green, K. (2011). It hurts so it is real: Sensing the seduction of mixed martial arts. Social and Cultural Geography, 12(4), 377-396. doi: 10.1080/14649365.2011.574796

Green, T. and Svinth, J. (Eds.) (2003). Martial arts in the modern world. Westport: Greenwood Publishing.

Grosz, E. (1994). Volatile bodies: Towards a corporeal feminism. Bloomington: Indiana University Press.

Guérandel, C., \& Mennesson, C. (2007). Gender construction in judo interactions. International Review for the Sociology of Sport, 42(2), 167-186. doi: $10.1177 / 1012690207084750$

Guthrie, S. (1995). Liberating the amazon: Feminism and the martial arts, in J. Ochshorn \& E. Cole (Eds.), Women's spirituality, women's lives (pp.107-120.). NY: The Haworth Press.

Halbert, C. (1997). Tough enough and woman enough: Stereotypes, discrimination, and impression management among women professional boxers. Journal of Sport and Social Issues, 21(1), 7-36. doi: 10.1177/019372397021001002

Hargreaves, J. (1997). Women's boxing and related activities: Introducing images and meanings. Body \& Society, 3(4), 33-49. doi: 10.1177/1357034X97003004002

Heaton, J. (2008). Secondary analysis of qualitative data: An overview. Historical Social Research, 33(3), 33-45. Retrieved from http://hsr-trans.zhsf.unikoeln.de/hsrretro/docs/artikel/hsr/hsr2008_1083.pdf

Hollander, J. (2004). I can take care of myself: The impact of self-defense training on women's lives. Violence Against Women, 10(3), 205-235. doi:

$10.1177 / 1077801203256202$

Jennings, G.B. (2010). Fighters, thinkers, and shared cultivation: Experiencing transformation through the long-term practice of traditionalist Chinese martial arts. (Unpublished doctoral dissertation). University of Exeter: UK.

Kvale, S., \& Brinkmann, S. (2008). Interviews: Learning the craft of qualitative research interviewing. London: Sage.

Lenskyj, H. (1986). Out of bounds: Women, sport and sexuality. Toronto: The Women's Press.

Lökman, P. (2010). Becoming aware of gendered embodiment: Female beginners learning aikido, in E. Kennedy \& P. Markula (Eds.), Women and exercise: The body, health and consumerism (pp.266-279.). London: Routledge.

Lorber, J. (2000). Using gender to undo gender. Feminist Theory, 1(1), 79-95. doi: $10.1177 / 14647000022229074$

Macpherson, H. (2009). Articulating blind touch: Thinking through the feet. The Senses and Society, 4(2), 179-193. doi: 10.2752/174589309X425120

McCaughey, M. (1997). Real knockouts: The physical feminism of women's self-defense. London: New York University Press.

McCaughey, M. (1998). The fighting spirit: Women's self-defense training and the discourse of sexed embodiment. Gender \& Society, 12(3), 277-300. doi:

$10.1177 / 0891243298012003003$ 
McDonagh, E., \& Pappano, L. (2008). Playing with the boys: Why separate is not equal in sports. New York: Oxford University Press.

McNaughton, M.J. (2012). Insurrectionary womanliness: Gender and the (boxing) ring. The Qualitative Report, 17, 1-13. Retrieved from http://www.nova.edu/ssss/QR/QR17/mcnaughton.pdf

Mennesson, C. (2000). 'Hard' women and 'soft' women: The social construction of identities among female boxers. International Review for the Sociology of Sport, 35(1), 21-33. doi: $10.1177 / 101269000035001002$

Messner, M.A. (1988). Sport and male domination: The female athlete as contested ideological terrain. Sociology of Sport Journal, 5(3), 197-211. Retrieved from http://journals.humankinetics.com/ssj-backissues/SSJVolume5Issue3September/SportsandMaleDominationTheFemaleAthleteasCon testedIdeologicalTerrain

Messner, M.A. (2002). Taking the field: Women, men, and sports. London: University of Minnesota Press.

Paradis, E. (2012). Boxers, briefs or bras? Bodies, gender and change in the boxing gym. Body \& Society, 18(2), 82-109. doi: 10.1177/1357034X12440829

Paterson, M. (2006). 'Seeing with the hands': Blindness, touch and the Enlightenment spatial imaginary. The British Journal of Visual Impairment, 24(2), 52-59. doi:

$10.1177 / 0264619606063399$

Rao, S. (2008). Oos sensai! Oos sempai! A karate school and lessons on inclusion. International Journal of Inclusive Education, 12(3), 281-299. doi: $10.1080 / 13603110601103238$

Ryan, M. (2011). I did not return a master, but well cudgelled was I: The role of 'body techniques' in the transmission of Venezuelan stick and machete fighting. The Journal of Latin American and Caribbean Anthropology, 16(1), 1-23. doi: 10.1111/j.19354940.2011.01122.x

Sheets-Johnstone, M. (2011). The primacy of movement (Expanded second edition). Amsterdam: John Benjamins.

Sparkes, A. (2009). Ethnography and the senses: Challenges and possibilities. Qualitative Research in Sport and Exercise, 1(1), 21-35. doi: 10.1080/19398440802567923

Spencer, D.C. (2009). Habit(us), body techniques and body callusing: An ethnography of mixed martial arts. Body \& Society, 15(4), 119-143. doi: 10.1177/1357034X09347224

Spencer, D.C. (2011). Ultimate fighting and embodiment: Violence, gender, and mixed martial arts. Abingdon: Routledge.

Theberge, N. (1987). Sport and women's empowerment. Women's Studies International Forum, 10(4), 387-393. doi: 10.1016/0277-5395(87)90056-2

Travers, A. (2008). The sport nexus and gender injustice. Studies in Social Justice, 2(1), 79101. Retrieved from http://ojs.uwindsor.ca/ojs/leddy/index.php/SSJ/article/viewArticle/670

Wachs, F.L. (2005). The boundaries of difference: Negotiating gender in recreational sport. Sociological Enquiry, 75(4), 527-547. doi: 10.1111/j.1475-682X.2005.00135.x

Wacquant, L.J.D. (2004). Body \& soul: Notebooks of an apprentice boxer. Oxford: Oxford University Press. 
Weedon, C. (1999). Feminism, theory, and the politics of difference. Oxford: Blackwell.

West, C., \& Zimmerman, D.H. (1987). Doing gender. Gender \& Society, 1(2), 125-151. doi: $10.1177 / 0891243287001002002$

Zarrilli, P.B. (1998). When the body becomes all eyes: Paradigms, discourses and practices of power in kalarippayattu, a South Indian martial art. New Delhi: Oxford University Press. 